\title{
Estratégias de inserção produtiva dos migrantes do sul do Brasil no Mato Grosso no período pós-1990
}

\author{
Cristiano Desconsi *
}

Este trabalho trata do movimento migratório do sul do Brasil para o Mato Grosso no período pós-1990, empreendido por um grupo de famílias cuja forma de vida e trabalho está e esteve associada à agropecuária. O objetivo central é analisar os caminhos seguidos e as estratégias de "entrada" no Mato Grosso acionadas pelos atuais "pequenos" proprietários rurais da microrregião do Alto Teles Pires. Consideramos que a categoria dos "pequenos" proprietários rurais é composta pelos chacareiros e assentados. Os primeiros são agricultores que possuem uma propriedade rural no entorno das cidades com área que varia de três a dez hectares e desenvolvem atividades agrícolas e não agrícolas. Já os assentados, são agricultores cujo acesso à terra se efetivou através de título de posse em projetos de assentamentos rurais via projetos desencadeados pelo Estado brasileiro. Possuem áreas de terra que variam de 50 a 250 hectares.

Para realizar o estudo sobre migração enquanto processo social, primeiro tomamos os atores (migrantes) como agentes coletivos, compreendendo as trajetórias no meio social em que as encontramos interagindo com os contextos sócio-históricos e outras forças estruturais e vetores que interferem no processo migratório (SILVA e MENEZES, 2006). É importante compreendemos que existem forças estruturais que constroem e desconstroem dinâmicas no espaço social (BOURDIEU, 1990). Mesmo que estejamos analisando, neste trabalho, os grupos

\footnotetext{
* Sociólogo, mestre em Ciências Sociais em Desenvolvimento, Agricultura e Sociedade - CPDA - UFRRJ, consultor do Programa das Nações Unidas para o Desenvolvimento - PNUD Brasília - DF.
} 
familiares que se deslocam, compreendemos que estes o fazem em meio a uma trama de relações sociais que envolvem outros migrantes, não migrantes e também as chamadas "comunidades de espectadores", que permanecem nos locais de origem, mas conectados através das redes sociais (SAYAD, 1998). Para analisar esse deslocamento, tomamos a família (casal mais os filhos que migram conjuntamente) como categoria analítica. A análise do deslocamento geográfico, geralmente concebida, em termos locais, como deslocamento da família, lançou mão da noção de trajetória, que não se reduz a um sentido puramente geográfico (BOURDIEU, 1996).

O trabalho apresenta três partes. Na primeira, situamos de forma breve os fluxos e o contexto da microrregião no período pós-1990, situando as trajetórias do grupo estudado. Na segunda parte, analisamos as estratégias de inserção produtiva e social acionadas pelos atores na região de destino (Mato Grosso). 0 trabalho agrícola ("de peão"), os projetos de assentamentos rurais e as chácaras se configuram como caminhos trilhados pelas famílias. Os atores sociais designados de "pequenos" se movimentam no ponto de destino buscando espaços de inserção produtiva e locais de residência. Na terceira parte, discutimos a luta pelo acesso à terra e ao trabalho, além da busca pela acumulação de patrimônio, como aspectos centrais para compreender os deslocamentos, exigindo dos atores uma avaliação constante de qual é o "melhor lugar" para permanecer ou estabelecer nova etapa migratória.

\section{Fluxos Migratórios no período pós-1990}

Nas décadas de 1990 e de 2000, os fluxos migratórios da Região Sul do Brasil em direção aos estados do Centro-Oeste e Norte ganham intensidade. $O$ estado do Mato Grosso apresenta um dinamismo demográfico que é indicativo do avanço da fronteira agrícola e da urbanização. Nesse sentido, a microrregião do Alto Teles Pires apresenta destaque pela "tomada" da soja e, associada a ela, uma crescente urbanização, especialmente em Sorriso e Lucas do Rio Verde, cidades que margeiam a BR-163, e que vêm se consolidando como polos regionais nas atividades dos setores agroindustriais e de serviços. O município de Sorriso, entre 1991 e 2000, teve um incremento populacional de 121\%; já de 2001 a 2007 o aumento foi de $53,45 \%$, o que corresponde a 19.031 habitantes. O município de Tapurah apresentou decréscimo populacional, fato que se explica em grande parte pela emancipação de Ipiranga do Norte e de Itanhangá, no ano de 2005. Comparativamente aos municípios desta microrregião, o estado do Mato Grosso teve um crescimento populacional de $2,4 \%$ a.a., enquanto nesta microrregião o índice ficou em 8\% (CUNHA et. al., 2004).

Ao mesmo tempo, os deslocamentos populacionais apresentam dinâmicas particulares, o que remete à necessidade de compreendê-los para além das análises restritas aos espaços de origem e destino, ou somente pelos saldos migratórios e fluxos predominantes, ou, ainda, por mais relevante que seja no caso da microrregião em questão, pela crescente urbanização (BRITO, 2000). 
A urbanização, nesse sentido, possui uma correlação direta com a dinâmica ligada às atividades agropecuárias, na medida em que tais municípios se tornam polos do setor de agroindustrialização e prestação de serviços, assim como locais de residência de trabalhadores. "O conhecimento do Cerrado, do desbravamento, começou de 90 pra cá. Antes, era derrubar mato para plantar arroz. $O$ forte mesmo depois de 1992 e 1993, aí começou o povo mesmo a trabalhar na terra, a usar a terra velha." ${ }^{1}$ Nessa dinâmica do desenvolvimento, a agricultura tem um papel importante não somente como produtora de alimentos e matérias-primas, mas também como mercado para os outros setores do complexo agroindustrial, com destaque para o setor de máquinas, insumos e sementes. Ganham destaque, também, culturas agrícolas destinadas especialmente à exportação ou à agroindústria, como é o caso da soja, baseadas nas dinâmicas dos preços internacionais. Estão presentes, nessa dinâmica de expansão, fatores como a criação de infraestrutura (estradas, armazéns e serviços) (MARTINE e GARCIA, 1987).

Com "o conhecimento do desbravamento do Cerrado", como relatou o comerciante entrevistado, a agricultura, especialmente após a década de 1990, mediante o processo de incorporação de novas áreas ao sistema produtivo, tem condições de ganhar escala e rapidez. "Você pega daqui pra Paranatinga [leste], $300 \mathrm{~km}$, é tudo aberto, tem armazém e está plantando soja. Pro outro lado [oeste], $300 \mathrm{~km}$ também, aqui tem uma expansão muito grande pra você trabalhar, pra você andar, pra você crescer." ${ }^{2}$ A expansão, nesse sentido, tem como pontos de referência a cidade de Sorriso e a BR-163. A narrativa do chacareiro é pertinente, pois aciona os elementos da oportunidade nas "áreas novas" e "o crescer", este como sinônimo de acumular "recursos" através do trabalho. A dinâmica da urbanização, porém, ocorre em confluência com políticas públicas de redistribuição de terras nos projetos de assentamentos de Reforma Agrária. A possibilidade de acesso à terra atrai famílias de migrantes do sul do Brasil, bem como produz um rearranjo na questão fundiária e nas migrações entre as microrregiões do próprio estado do Mato Grosso. As desapropriações para fins de Reforma Agrária, empreendidas pelo Estado brasileiro, vão ter nova ênfase na década de 1980 e vão ganhar destaque expressivo, pelo menos do ponto de vista numérico, na segunda metade da década de 1990. A tabela abaixo traz uma radiografia dos projetos e respectivos números de famílias assentadas no período de 1986 a 2003, no estado do Mato Grosso:

TABELA 1 - Assentamentos no Mato Grosso (1986-2003)

\begin{tabular}{|c|c|c|}
\hline PERÍODO & NÚMERO DE PROJETOS & NÚMERO DE FAMÍLIAS \\
\hline 1986- 1991 & 25 & 4247 \\
\hline $1991-1996$ & 77 & 15040 \\
\hline $1996-2001$ & 189 & 35493 \\
\hline 2001-2003 & 34 & 4450 \\
\hline TOTAL & 325 & 59230 \\
\hline
\end{tabular}

FONTE: Superintendência do INCRA do Mato Grosso. Tabulações Nepo Unicamp, 2003. (Adaptadas pelo autor, incluindo os dados dos projetos do governo do estado, INCRA e Projetos Casulo). 
De 1996 a 2001, o aumento de 35.493 famílias assentadas está relacionado diretamente à política governamental de Reforma Agrária levada a cabo especialmente no governo Fernando Henrique Cardoso (FHC). Com base nos dados atualizados do Ministério do Desenvolvimento Agrário, no período de 1995-2002, "o governo de FHC desencadeou 5.100 projetos, beneficiando 423.813 famílias". Desta quantidade, $35 \%$ se localizaram na região Centro-Oeste. Isto, em suma, situa os dados elencados acima sobre os assentamentos na região de estudo. A pressão dos movimentos sociais do campo, na década de 1990, em meio a um conjunto de conflitos e massacres, demarca a luta pela terra e desencadeia desapropriações como resposta a esses movimentos. As regiões de maior tensão social, devido às ações de ocupação e conflitos entre fazendeiros, posseiros e outros agentes, são os espaços onde se localizam as "manchas" de assentamentos, fato também identificado no Mato Grosso (LEITE e MEDEIROS, 2004).

\section{Estratégias de acesso à terra e ao trabalho}

Uma das questões que permeia as discussões sobre o processo migratório está relacionada ao tipo de inserção (produtiva) dos migrantes no novo espaço. O que estaria sendo levado em conta por parte dos atores migrantes na definição do local de residência e do tipo de inserção produtiva? Foi recorrente, nas narrativas dos atores, a referência ao momento de migrar e ao local para onde se pretendia migrar. A fala do agricultor L. M. sintetiza bem essas referências: "Aqui no Mato Grosso temos que estar no lugar certo, no momento certo". Esta afirmação vem associada à observação de oportunidades de produzir a mobilidade social ou acumulação de patrimônio a fim de reproduzir o grupo familiar. No caso do conjunto das famílias, isto está associado ou ao acesso à terra e sua valorização ou ao trabalho agrícola (trabalho de peão) em fazendas e cidades em crescimento.

\section{Acesso e valorização das terras}

Perpassa as trajetórias desse grupo estudado a busca pela terra, ou ainda, a busca por mais terra. A terra é o meio de produção pelo qual, através do trabalho familiar, se pode obter a produção de subsistência e possibilitar as condições mínimas de acumulação de patrimônio visando à geração seguinte (filhos). Esta relação das famílias com a terra se constrói carregada de um conjunto de significados e representações dos camponeses (WOORTMANN, 1995). No Brasil, essa busca deve ser situada dentro de um processo histórico em que a reprodução dessas famílias sempre esteve associada a processos de expropriação de populações camponesas e de migração para novas fronteiras (MARTINS, 1981). Este fato pode ser identificado nos percursos das famílias de agricultores que por vezes saem de regiões do Rio Grande do Sul, perpassando diversas etapas até chegar ao Mato Grosso. Migrar é a possibilidade do acesso à terra, cuja disponibilidade está na fronteira. Assim, o Mato Grosso é o lugar de oportunidade, na busca pela autonomia da família. 
Nas novas fronteiras, um elemento central no "chamamento" das famílias de agricultores diz respeito à abundância de terras produzindo a ideia de que, além do lote inicial, seria possível aumentar o patrimônio familiar através da compra de outras áreas de terra. A propaganda também vinha associada a uma dimensão simbólica "do espaço", característica do Cerrado. É a representação do espaço supostamente vazio, que passará a ser incorporado, é onde vai ser estruturado o espaço social em conformidade com uma visão de mundo destes atores (ZART, 1998).

A insuficiência de terras na origem é ponto relevante e gerador de uma condição de crise que pressionou as famílias a migrar. A partir da unidade produtiva, essas famílias avaliaram que a quantidade de terra e de outros fatores de produção que possuíam eram fatores limitantes para o aumento da produção no tipo de atividade agrícola desenvolvida. Assim, a estratégia identificada para gerar aumento da renda familiar está associada à busca por "mais terra" em outras regiões do país.

A necessidade de mais terra, além da questão da herança, pode estar vinculada à modernização dos sistemas produtivos adotados na região Sul. As pesquisas que observam o deslocamento dos agricultores para a fronteira citam a relação entre a venda da terra no Sul, geralmente pequena no sistema de "colônias", e a possível aquisição de áreas maiores, mesmo nos assentamentos rurais (lotes de até 100 hectares) (SANTOS, 1993). Esta racionalidade, que objetiva ampliar o patrimônio pela aquisição de terras baratas, indica a possibilidade de o agricultor, ao dispor de mais terras, poder aumentar sua produção com vistas a reproduzir seu grupo familiar melhorando suas condições de vida.

No entanto, há outro elemento associado à busca por terras baratas: a perspectiva de valorização das mesmas. Chama a atenção, no caso dos assentamentos, o grau de valorização monetária, o preço praticado nos negócios. Essa valorização expressiva que chega, em algumas situações, a 1000 \% (especialmente nos primeiros cinco anos), gera uma tensão para a venda do lote sobre os agricultores assentados, sobretudo quando do enfrentamento de dificuldades financeiras, como ocorreu no caso dos assentados de Santa Rosa II, que acessaram o primeiro crédito e a Rede de Eletrificação Rural somente em 2005-06. Diante das dificuldades apresentadas, a pressão de compradores "de fora" aumenta.

A média do preço dos lotes gira em torno de 10 mil a 12 mil sacas de soja ou, convertendo nos valores praticados em agosto de 2008, aproximadamente $\mathrm{R} \$ 350.000,00$ a $\mathrm{R} \$ 400.000,00$ por lote de 80 a 100 hectares, no caso de áreas de terra há mais de três anos em cultivo. Nesse sentido, o preço da terra nesses assentamentos salta de $\mathrm{R} \$ 100,00$ por hectare para valores entre $\mathrm{R} \$ 3.200,00$ e $\mathrm{R} \$ 3.500,00$ por hectare, isso num espaço de tempo inferior a nove anos. Destaco que esta expressiva valorização monetária da terra não é fato que se constata somente nos assentamentos rurais, ela acontece em todas as áreas de terra desta microrregião. 
No caso do Cerrado mato-grossense, os agricultores que migram para estas terras nos anos recentes sabem que, além da terra e do trabalho, terão que ter "o recurso", ou seja, o capital (dinheiro, crédito, insumos, máquinas), a fim de "fazer agricultura e mexer com lavoura". Neste caso, pressupõem o uso de um aparato tecnológico a fim de tornar a terra produtiva. No entanto, transformar a terra bruta em terra de lavoura aumenta as expectativas de renda da terra, de seu valor de mercado e sua possibilidade de venda.

A dimensão da terra, os lotes em assentamentos e as chácaras são concebidos também como ativos financeiros de alta liquidez. Notoriamente, esta concepção não deve ser compreendida na análise, isoladamente, mas como resultado de uma confluência de fatores, entre os quais se destacam: a) a falta de capital financeiro e o acesso limitado ao crédito institucional e à assistência técnica; b) o temor de perda do lote por motivos de conflitos no assentamento (posseiros, atitude dos funcionários estatais) e do forte apelo e interesse de potenciais compradores, sejam fazendeiros ou mesmo outros agricultores do Sul mais capitalizados.

\section{O trabalho agrícola - “o peão"}

Outro componente presente nas trajetórias desses assentados e chacareiros é a passagem pelo trabalho agrícola, na categoria "trabalho de peão", segundo a denominação local. Esta categoria designa o trabalho de empregado submetido a um patrão; designa, acima de tudo, o empregado agrícola que, em geral, tem nas fazendas seu local de trabalho; representa o trabalho não autônomo, ou, dito em termos populares, "trabalhar no que é dos outros". Na medida em que a família nunca teve acesso à sua unidade de produção, ou na medida em que a família da geração anterior (dos pais) não conseguiu acumular patrimônio para reproduzir a geração dos filhos em novas unidades domésticas, o trabalho de peão aparece como meio para esta finalidade.

Inicialmente, convém refletir sobre as distinções que se apresentam associadas à denominação "trabalho de peão" a que estamos nos referindo, a partir dos casos analisados. Assim, de modo geral, caracterizamos quatro formas de trabalho associadas à designação "de peão":

1) A primeira refere-se ao emprego agrícola permanente, ou seja, o "peão fixo". É aquele que recebe remuneração mensal e por vezes alguma forma de bonificação no final da safra anual. O peão pode residir nas fazendas com a família ou em local próximo e se deslocar até a fazenda, que é o local de trabalho. Consideramos permanente esse trabalhador porque possui o vínculo de empregado, independente do ciclo agrícola.

2) Outra forma de "trabalho de peão" é o chamado safrista, o contratado para um determinado período do ciclo agrícola (plantio, colheita, por exemplo), com remuneração, em geral, por salário mensal naquele período, ou no caso de colheita, por porcentagem do produto colhido. Observando o ciclo agrícola, uma parte dos trabalhadores é contratada por período de seis a oito meses, que coincide com a estação das chuvas, que vai de outubro a abril. Nesse período 
é que são cultivadas as lavouras de soja, milho e algodão (principais culturas agrícolas desta microrregião). Terminado este ciclo agrícola, os trabalhadores são dispensados. Esta forma de trabalho engloba, especialmente, os operadores de máquinas, motoristas de caminhões e carregadores.

3) A terceira forma de "trabalho de peão" é o de empreita ou o de diarista. Neste caso, entram em cena trabalhos sazonais, associados às práticas agrícolas; envolvem a abertura do Cerrado, a atividade de "catação de raízes"3 , carregamento e descarregamento de caminhões, trabalho nos silos e armazéns. O pagamento é feito em valor monetário no final da atividade desenvolvida.

4) Uma quarta forma de trabalho, que também compõe a designação de peão, mas por vezes também a designação "de empregado", refere-se às atividades ligadas à formação das cidades e vilas. Os trabalhos de pedreiro (construção civil), em cooperativas de prestação de serviços e de motorista são exemplos dessa forma, que possui remuneração por empreita ou pagamento diário.

Com essa tipificação, construída a partir das experiências vividas pelas famílias, queremos deixar claro o que designamos quando utilizamos o termo "peão". De igual modo, ela é instrumento para compreender como e quando essas formas de trabalho foram acionadas pelos atores em suas trajetórias, bem como trazer indicações de mudanças que ocorreram no padrão de emprego agrícola nessa região.

Nas décadas de 1980 e 1990, que se caracterizam como principal período de migração do Sul com destino às áreas rurais dessa microrregião, duas formas de inserção nesse novo espaço estavam presentes de maneira mais intensa. Na primeira forma de inserção, o migrante tornou-se proprietário de terra ou por carregar em suas bagagens algum "recurso" acumulado, ou por ter sido beneficiado, no Mato Grosso, pelas políticas públicas de incentivo ao desenvolvimento efetivadas nesse período. Na segunda forma, o migrante entrou no Mato Grosso como peão. Nas trajetórias dos grupos estudados verificamos que $o$ trabalho de peão configurou-se como estratégia para acumular algum patrimônio visando a compra de lote (em assentamento ou loteamento para chácaras) ou, ainda, visando investimentos iniciais sobre o lote adquirido, para a "arrancada" das atividades produtivas.

A forma de trabalho agrícola "atrativa", por volta de 1998, no ato da chegada dos migrantes, estava associada ao emprego permanente nas fazendas, cujas condições permitiram juntar "recursos" para, posteriormente, buscar o acesso à terra própria. Morar na fazenda evita investimentos iniciais em aluguel ou mesmo na construção de algum tipo de residência para morar; os salários mensais garantem a manutenção da família. Buscar o trabalho de peão na sua forma de emprego permanente configura-se oportuno ao garantir uma segurança em relação à renda mensal e à moradia.

Essas famílias residiam nas fazendas onde trabalhavam, recebiam remuneração mensal entre dois a três salários, mais uma bonificação no fim da safra de soja, correspondente a 300 sacas. Outro elemento relevante, nestes 
casos de inserção pelo trabalho de "peão fixo", diz respeito ao período em que isto acontece. Na década de 1990 é que essa forma de trabalho agrícola se configura como possibilidade. A permanência o ano todo na fazenda está associada ao trabalho de operador de máquinas e equipamentos, à atividade de desmatamento de novas áreas ou, ainda, à função de zelador ou caseiro.

As outras formas de "trabalho de peão" também são recorrentes nas trajetórias do conjunto das famílias analisadas. Trabalhar "pra fora" foi a forma encontrada para a manutenção da família nos primeiros anos e, também, nos casos em que não se dispunha de "recurso" acumulado para investir no lote. O conjunto de serviços ligados à transformação produtiva do Cerrado em área de lavoura gera uma demanda intensa de trabalho durante um período de dois a três anos.

Nos anos recentes, os atores apontam uma mudança estrutural no emprego agrícola. Apresentam-se cada vez menos postos de trabalho para realizar as mesmas atividades agrícolas nas fazendas; esgotam-se as possibilidades de expansão de áreas nesses municípios; novas formas de contratação dos peões se configuram, restringindo-se a forma permanente a alguns caseiros e gerentes.

Os trabalhadores contratados como peões tendem, cada vez mais, a permanecer na condição de temporários, safristas e diaristas. Os trabalhadores contratados "por safra" ou ano agrícola (seis a oito meses) vão ter carteira assinada e receber no período pós-vencimento deste contrato de trabalho, por três meses, um seguro-desemprego com salários de $R \$ 1.000,00$ a $R \$ 1.500,00$; outro grupo de peões é contratado no período de plantio ou no de colheita, isoladamente. Ultimamente, inovações tecnológicas introduzidas nas atividades agropecuárias da região (seja pela incorporação de novas máquinas, seja pela adoção de novas práticas agrícolas) são apontadas como fatores de redução de oportunidades de trabalho nas atividades agrícolas desenvolvidas na região.

Cabe aqui reforçar a importância de datar historicamente os fatos, com suas nuances, relacionados ao processo migratório. $O$ trabalho de peão, que vem se reduzindo, exige cada vez maior qualificação dos trabalhadores e, ao mesmo tempo, o predomínio cada vez maior de contratos de curto período geradores de insegurança para as famílias que dependem do emprego agrícola. Paralelamente, este fato reforça a ideia que associa o acesso à terra (de modo especial chácaras e assentamentos) a um "porto seguro", apesar dos problemas e dificuldades já apontados a partir dos próprios atores. Cada vez mais é recorrente a busca por intercalar diversas estratégias produtivas e de acesso ao trabalho, envolvendo todos os membros da família. As múltiplas configurações de acesso ao trabalho e as respectivas estratégias das famílias envolvidas são temas que devem ser objeto de reflexão mais aprofundada em outros estudos.

\section{Os recursos da família na chegada em Mato Grosso}

$\mathrm{Na}$ análise das trajetórias construídas pelos migrantes, que implicaram em várias etapas de migração associadas às estratégias do "ser peão", vale a tentativa de identificar quais os parâmetros que influenciaram a escolha do local 
de destino das famílias. No âmbito desta pesquisa, foi possível constatar que, no fluxo migratório do Sul para o Mato Grosso, as condições, os recursos de que dispunham as famílias apresentaram-se como fatores de definição, não somente da "entrada", como também de uma nova etapa migratória dentro das trajetórias do grupo. No que diz respeito à opção pelo acesso à terra nos assentamentos e não em outros projetos de colonização empreendidos no Mato Grosso, as respostas giram em torno de recursos disponíveis naquele momento da migração: "Eu não vim com dinheiro, eu vim só com o comecinho. Se eu tivesse dinheiro teria comprado um lote de escritura."4

Os assentamentos rurais são considerados como a possibilidade de acesso à terra, principalmente para aquelas famílias que dispõem de "pouco recurso". Nesse caso, outras duas características dos assentamentos rurais devem ser observadas. Uma delas refere-se ao parcelamento da terra em lotes menores (em geral de 50 a 90 hectares), ao contrário de projetos agropecuários empreendidos por empresas colonizadoras, corretores de imóveis ou imobiliárias, que operam com áreas maiores (em geral acima de 400 hectares). Para comprar grandes áreas de terra e proceder à conversão da vegetação natural em área de lavoura, os recursos exigidos ficam muito além da disponibilidade dessas famílias ${ }^{5}$. Outra característica é que os assentados não possuem o título de proprietário do lote (escritura), mas sim a concessão de posse. Este elemento influi no preço das terras nos assentamentos estudados, ou seja, é maior o preço das terras nas áreas circunvizinhas que possuem a documentação de escritura.

As trajetórias dos migrantes do Sul "com pouco recurso", rumo aos assentamentos como destino ou como nova etapa migratória, se confirmam quando observamos as tratativas antes da migração e as viagens para conhecer. $O$ grande número de assentamentos no Mato Grosso criou expectativas de acesso à terra para esses migrantes. Para as famílias que trabalhavam em empregos agrícolas, a busca pela terra é cultivada como uma espécie de sonho, desde a migração do Sul para o Centro-Oeste.

Nesse sentido, identificamos que, nesta busca pela terra, cotidianamente eram "mapeadas" as regiões, no Mato Grosso, onde estavam ocorrendo desapropriações de terra entre os anos de 1996-2001, conforme descreve um dos assentados entrevistados: "Até uma época eu e o Edson saímos e fomos pra baixo da Vila Rica olhar umas terras". ${ }^{6}$ Essa viagem, descrita pelo assentado "para olhar as terras", aconteceu no ano de 2001 e compreendeu um roteiro exatamente em municípios do Mato Grosso ${ }^{7}$ onde estavam sendo implantados vários Projetos de Assentamentos, com destaque para o período de 1996 a 2001. As viagens para conhecer o Mato Grosso, com vistas a fechar negócios de compra de terra (lotes), também são componentes das trajetórias das demais famílias estudadas, que estabeleceram percursos pelas regiões onde estão situados Projetos de Assentamentos.

Em suma, evidenciamos que o recurso disponível (patrimônio acumulado) é elemento pertinente na definição de para onde e quando a família vai empreender sua migração. Talvez se tomássemos um grupo de "grandes" 
proprietários desta mesma microrregião, observando a temporalidade de sua migração e os locais de inserção, verificaríamos configurações diferenciadas no próprio espaço geográfico. Os migrantes do Sul que dispõem de "pouco recurso" avaliam o acesso à terra nos projetos de assentamento rurais, mapeando os locais de novos projetos, bem como a sua situação; mapeiam da mesma forma, como um horizonte possível, novas regiões que estão em processo de expansão, buscando o trabalho "de peão".

\section{Considerações finais}

O presente estudo sobre o processo migratório permite afirmar que os deslocamentos do Sul rumo ao Oeste não só permanecem no período pós-1990, como se intensificam, ganhando novos contornos. $O$ foco analítico, a partir do grupo social que chamamos de "pequenos" proprietários rurais, permitiu uma abordagem diferenciada pelo olhar sobre os migrantes do Sul. Muito presente a busca por ascensão social e relevante enquanto elemento simbólico associado ao Mato Grosso, as famílias analisadas nesta pesquisa melhoraram suas condições de vida, apesar de não mudarem sua posição social. Este fato decorre de uma complexidade de fatores, que não cabe aqui analisar, cada um deles contribuindo, no que tange ao processo migratório, para esclarecer que a direção específica das trajetórias daqueles migrantes "de poucos recursos" se configurou em percursos peculiares, locais de trabalho e residência específicos destas famílias na sua chegada ao Mato Grosso.

Os assentamentos rurais, as chácaras, as fazendas e as cidades e vilas em formação são os espaços onde em geral as trajetórias perpassaram. Paralelamente, nestes locais as famílias alternaram períodos de suas trajetórias desempenhando algum dos "tipos" de trabalho de peão, além da condição de proprietários rurais em chácaras e assentamentos. Vale destacar que todas estas funções desempenhadas pelas famílias visam a acumulação de patrimônio a fim de reproduzir o grupo familiar. $\mathrm{O}$ acesso à terra é compreendido pelo grupo dos "pequenos" como o caminho para tal fim. Os caminhos presentes na trajetória (trabalho de peão em suas diversas formas, interações e apoio da rede social na qual cada família está inserida) são percebidos como etapas nesta busca, também associada ao ciclo de vida como "coisa para gente nova".

No que tange à luta por terra no Mato Grosso, agregamos um aspecto que serve como mecanismo de acumulação, que é a valorização dessas terras. Este elemento apresenta uma contradição, pois, ao mesmo tempo em que possibilita a uma família assentada um abrupto crescimento no valor de seu patrimônio, de outra parte é a terra com alto valor de mercado e ou sua facilidade em se transformar em ativo financeiro um dos aspectos que pressiona a concentração da terra e inviabiliza, em curto período de tempo, a possibilidade de permanência, no lote ou sítio, das famílias que possuem pouco capital ("recursos").

Nesta busca pela terra nos anos 1990, os assentamentos, entendidos como políticas públicas promovidas pelo Estado, foram fundamentais. Paralelamente, 
esteve presente a expansão dos empreendimentos agropecuários, que foram concentrando a terra enquanto base para consolidação dos polos microrregionais nos setores de comércio, indústria e serviços particularmente, em Sorriso e Lucas do Rio Verde. Nessas cidades, o crescimento vertiginoso permitiu a viabilização de pequenas chácaras no entorno e, também, a geração de trabalho agrícola na fase de derrubada e de expansão das áreas cultivadas e de construção das cidades.

Os atores sociais aqui pesquisados percebem este movimento que poderia ser considerado cíclico e de curta duração. Nesse sentido, avaliam constantemente o "momento certo e o lugar certo" na fronteira, ou seja, para onde poderia ser mais oportuna a migração diante das suas condições econômicas, sociais e culturais, o que implica na decisão entre as possibilidades de permanecer e de migrar. As trajetórias dessas famílias revelaram a condição de provisoriedade desse grupo, confirmada pelas avaliações entre o permanecer e o migrar como componentes de seu cotidiano e do conjunto de suas relações sociais, em geral, operadas como um processo negociado.

\section{Notas}

1 - Entrevista com N. H., Comerciante, município de Sorriso MT, 25/05/08.

2 - Entrevista com A. T., Chacareiro, Sorriso MT, 04/06/08.

3 - A atividade de catação de raízes consiste no trabalho realizado após a derrubada da vegetação natural do Cerrado. Os primeiros revolvimentos do solo com grade expõem na superfície da área as raízes da vegetação que existia ali. Nesta situação, são contratados trabalhadores para fazer a catação manual dessas raízes, que são amontoadas e, geralmente, queimadas na sequência do trabalho.

4 - Entrevista com A. H., assentado, Boa Esperança MT, 19/06/08.

5 - A liquidez de um ativo compreende o grau de facilidade ou dificuldade que determinado bem apresenta para ser vendido. Na argumentação de Plata (2006) há uma relação entendida como inversa entre o tamanho do imóvel (dimensão) e o preço. Segundo este autor, os imóveis de menor dimensão são mais fáceis de ser vendidos por apresentarem maior demanda de compradores.

6 - Entrevista com I. F., assentado, Boa Esperança MT, 10/06/08.

7 - Nos municípios de Colniza, Confeza e Porto Alegre do Norte no período de 1996-2001 foram assentadas, respectivamente, 2172, 1130 e 370 famílias. (Fonte: Superintendência do INCRA Mato Grosso, Tabulações Nepo-Unicamp, adaptado pelo autor).

\section{Referências}

BOURDIEU, Pierre. Coisas ditas. São Paulo: Brasiliense, 1990.

BOURDIEU, Pierre. A ilusão biográfica. In: FERREIRA, Maristela de Morais e AMADO, Janaína. Usos e abusos da história oral. Rio de Janeiro: FGV, 1996, 8a ed.

BRITO, Fausto. Brasil, final de século: A transição para um novo padrão migratório? Caxambu, XII Encontro da ABEP, 2000. Disponível em: <www.abep.nepo.unicamp.br>. Acesso em: 11 nov. 2010.

CUNHA, José Marco Pinto da et al. Diagnósticos Regionais do Estado do Mato Grosso. Campinas: NEPO, Texto 49, 2004.

DESCONSI, Cristiano. A marcha dos pequenos proprietários rurais: Trajetórias de migrantes do Sul do Brasil em Mato Grosso. Rio de Janeiro: Ed. E-papers, 2011.

LEITE, Sergio Pereira e MEDEIROS, Leonilde. Marchas e contra-marchas na política agrícola. 
In: FALEIROS, Vicente de Paula; NUNES, Seleme; FLEURY, Sônia. A era do governo FHC e o governo Lula: transição? Brasília: INESC, 2004.

MARTINE, George e GARCIA, Ronaldo Coutinho. Os impactos sociais da modernização agrícola. São Paulo: Caetés, 1987.

MARTINS, José de Souza. Os camponeses e a política no Brasil. São Paulo: Hucitec, 1981.

PLATA, Ludwig Einstein Agurto e REYDON, Basttian Phillip. Políticas de Intervenção no Mercado de Terras no governo FHC. In: REYDON, Basttian Phillip e CORNÉLIO, Francisca Meide Maemura (orgs.). Mercado de Terras no Brasil: Estrutura e Dinâmica. Brasília: Núcleo de Estudos Agrários, 2006.

SANTOS, José Vicente Tavares dos. Matuchos, exclusão e luta: do Sul para a Amazônia. Petrópolis: Vozes, 1993.

SAYAD, Abdelmalek. A imigração e os paradoxos da alteridade. São Paulo: Edusp, 1998.

SILVA, Maria Aparecida e MENEZES, Marilda. Migrações rurais no Brasil: velhas e novas questões. Brasília: Núcleo de Estudos Agrários, 2006. Disponível em: <www.nead.org. $\mathrm{br}$ /memoriacamponesa/arquivos/leitura/Migracoes_Rurais_no_Brasil_velhas_e_novas_ questoes.pdf >. Acesso em: 09 dez. 2009.

WOORTMANN, Ellen. Herdeiros, compadres e parentes: os colonos do Sul e os sitiantes do Nordeste. Brasília: EDEUB / Hucitec, 1995.

ZART, Laudemir Luiz. Desencanto na Nova Terra: Assentamento no município de Lucas do Rio Verde MT na década de 80. Cáceres: UNEMAT, 1998.

\title{
RESUMO
}

Este trabalho trata do processo migratório do sul do Brasil para o Mato Grosso no período pós1990. Partimos do pressuposto de que este fluxo migratório apresenta uma heterogeneidade de grupos sociais com suas experiências que produzem relações que se modificam em cada período histórico. O objetivo central é analisar os caminhos e as estratégias de "entrada" no Mato Grosso desencadeadas pelos atuais pequenos proprietários rurais. A partir da análise das trajetórias, na primeira parte é construída uma contextualização que dialoga com o processo de desenvolvimento desencadeado na região; num segundo momento aprofunda a análise sobre a "chegada" desses atores sociais no Mato Grosso. Os atores sociais designados de "pequenos" se movimentam no ponto de destino buscando espaços de inserção produtiva e locais de residência. As lutas pelo acesso à terra e ao trabalho são centrais neste aspecto, exigindo dos atores uma avaliação constante de qual o "melhor lugar" para permanecer ou estabelecer nova etapa migratória.

Palavras-chave: agricultores; sul do Brasil; Mato Grosso.

\begin{abstract}
The article focuses on the migration processes experienced by peasant families from the south of Brazil to Mato Grosso state in the post-1990s period. We base our study on the assumption that this migratory flow shows a heterogeneity of social groups with their experiences which produce different relations in each historical moment. The main goal is to analyze the path and strategies of the "entering" in Mato Grosso by small rural land owners. From the analysis of the trajectories, we first contextualize the development process of the region; in a second moment, we deepen the analysis about the "arrival" of these social actors to Mato Grosso. The so-called "small" social actors move about in their destination seeking spaces for inserting themselves into production and finding a place to live. The struggle for the access to land and to work are key in this respect, requiring a constant assessment by the actors regarding the "best place" to settle or establishing a new migration step.
\end{abstract}

Keywords: farmers; Southern Brazil; Mato Grosso. 